\title{
Nitrogen determination in micas of metamorphic rocks
}

\author{
F. J. Ager ${ }^{a, b}$, M. P. Mata ${ }^{c}$, M. D. Ynsa ${ }^{d}$, M. A. Respaldiza ${ }^{b}$, B. Goffé ${ }^{e}$ and F. Nieto ${ }^{f}$ \\ ${ }^{a}$ Depto. Física Aplicada I, Escuela Universitaria Politécnica, Universidad de Sevilla, C. Virgen \\ de Africa 7, E-41011 Sevilla, Spain
}

${ }^{b}$ Centro Nacional de Aceleradores, Av. Thomas A. Edison, E-41092 Sevilla, Spain

'Depto. Geología, Fac. Ciencias del Mar y Ambientales, Campus Rio San Pedro, s/n, E-11510 Puerto Real, Cádiz, Spain

'Centre d'Etudes Nucléaires de Bordeaux-Gradignan, IN2P3-CNRS, BP 120, 33175 Gradignan Cedex, France

eUMR 8538, Lb. Geologie, ENS, 24, Rue Lhomond, F-75231 Paris Cedex 05, France

fDpto. Mineralogía y Petrología, Fac. Ciencias, Av. Fuentenueva s/n, E-18002 Granada, Spain

\begin{abstract}
Micas are minerals that provide large amounts of information regarding geological processes, because of the sensitivity of their chemical composition to temperature, pressure and deformation of rocks in which they form. Rocks under analysis are formed of different minerals with variable grain size. Mica grain size may vary between 5 and $10 \mu \mathrm{m}$ and approximately correspond to the chemical formula $\left(\mathrm{Si}_{3.2} \mathrm{Al}_{0.8}\right) \mathrm{O}_{10}\left(\mathrm{Al}_{1.9} \mathrm{Fe}_{0.05} \mathrm{Mg}_{0.1}\right)(\mathrm{OH})_{2}\left(\mathrm{~K}_{0.75} \mathrm{Na}_{0.05}\right)$, being distinguishable from other minerals because of their composition and their morphology in secondary electron images and specially backscattered electron (BSE) images. $\mathrm{NH}_{4}$, when present, would partially substitute $\mathrm{K}$ in the previous formula. In some cases $\mathrm{NH}_{4}$-rich micas (tobelites) have been described coexisting with the corresponding K-rich micas, but the actual $\mathrm{NH}_{4}$ content of normal K-rich micas is still unknown. Low $\mathrm{N}$ content makes necessary to use nuclear reactions such as ${ }^{14} \mathrm{~N}(\mathrm{~d}$, py $){ }^{15} \mathrm{~N}$ at $1.4 \mathrm{MeV}$ and its cascade of intense $\mathrm{y}$-rays. For the quantification and localization of nitrogen on the surface of the samples, PIGE analysis was carried out in the vacuum microprobe line of the CNA, together with simultaneous micro-RBS and micro-PIXE analyses, giving a more comprehensive picture of sample structure and composition.
\end{abstract}

Keywords: Mica; Nitrogen; Ammonium; Nuclear microprobe; DIGE

PACS classification codes: 25.45.-z; 25.45.De; 20.30.Kv; 91.70.Dh

\section{Introduction}

Determination of the exact chemical composition of rock-forming minerals is fundamental in geology as such information provides a way to the knowledge of the physical-chemical conditions which have affected the rocks and hence about the history of the region during millions of years. During last decades powerful methods have been developed to determine the chemical composition of areas as small as less than the $\mu \mathrm{m}$. Nevertheless a basic weakness of such methods regards with light elements (e.g. H, Li, C, O or N). The problem of the low $\mathrm{K}$ content in some metamorphic rocks found in previous electron microprobe analysis (EMPA) of phengitic micas [1] and [2] has been already evaluated. Preliminary EMPA of Amorgos samples represent one of the most extreme cases in the problem of the composition of these phengites in a high-pressure environment.

Ammonium micas are frequent in organic-matter rich samples (as black shales), usually coexisting with the K-rich equivalent [3] but they are not expected in these type of samples, so 
an additional $\mathrm{NH}_{4}$ source should be evaluated. The question arises whether the presence of $\mathrm{NH}_{4}$ is more frequent in silicates than it was previously thought. The lack of data about a significant component of the mica could affect to the overall formula calculation as normalization is based in the total number of positive charges.

In order to determine low nitrogen contents in rocks, it is necessary to exploit the high sensitivity of IBA techniques such as nuclear reaction analysis (NRA) and particle induced $\mathrm{y}$-ray emission (PIGE) for light elements, together with particle induced X-ray emission (PIXE) for heavier elements. Besides, the use of a nuclear microprobe allows obtaining quantitative or semiquantitative elemental distribution maps of main and trace elements with high resolution and sensitivity. An appropriate method for the determination of the nitrogen contents is the deuteroninduced $\mathrm{y}$-ray emission (DIGE or d-PIGE) using the ${ }^{14} \mathrm{~N}(\mathrm{~d}, \mathrm{py}){ }^{15} \mathrm{~N}$ nuclear reaction [4], [5] and [6]. The high energy $\mathrm{Y}$-rays emitted $(7298$ and $8310 \mathrm{keV})$, have enough yield for analytical purposes. In this work the ${ }^{14} \mathrm{~N}(\mathrm{~d}, \mathrm{py}){ }^{15} \mathrm{~N}$ nuclear reaction at a deuteron energy of $1.4 \mathrm{MeV}$ is employed to measure low nitrogen contents in an Amorgos sample by means of DIGE and the overall composition of the mica by means of deuteron-induced X-ray emission (DIXE).

\section{Experimental}

\subsection{Sample description}

The island of Amorgos is situated at the South-east margin of the Cycladic Islands (Greece) and consists of a Mesozoic high-P metamorphic sequence consisting mainly of carbonates, metaconglomerates, quartzite and schists with some intercalated metabauxite lenses at the Northeastern part. The Amorgos metabauxites are affected by a low-grade, high-P metamorphism that is characterized by ferrocarpholite. The $P-T$ conditions at metamorphism for the Amorgos metabauxites were estimated as $300-350^{\circ} \mathrm{C}$, for a pressure higher than $12 \mathrm{kbar}$ as indicated by the diaspore-quartz assemblage [7]. The sample of this study is a metabauxite, mainly composed of diaspore, hematite and minor chlorite with ferrocarpholite, pyrophyllite and paragonite-muscovite assemblage. The studied areas correspond to veins made of ferrocarpholite-chlorite-quartz, paragonite-phengite assemblages.

\subsection{Ion beam analysis}

Microbeam analysis was performed with $1.4 \mathrm{MeV}$ deuterons focused to a $3 \times 3 \mu \mathrm{m}^{2}$ beam normal to the sample, using the CNA scanning nuclear microprobe [8]. For the analysis of rock samples PIXE elemental maps of $1000 \times 1000 \mu \mathrm{m}^{2}$ using a proton current of $100-300 \mathrm{pA}$ were generated in order to determine element distribution and locate the areas where mica is present. For the quantification of the micas, analyses were performed in selected areas of $30 \times 30 \mu \mathrm{m}^{2}$, opening the object slits to increase the beam current without worsening the resolution to more than $10 \times 10 \mu \mathrm{m}^{2}$. PIXE and backscattering spectrometry were carried out simultaneously. PIXE spectra were collected using a Sirius $80 \mathrm{Si}(\mathrm{Li}) \mathrm{X}$-ray detector manufactured by Gresham placed at $45^{\circ}$ to the beam with a $50 \mu \mathrm{m}$ Mylar ${ }^{\circledR}$ filter. Backscattered protons were detected using a surface barrier detector with an active area of $300 \mathrm{~mm}^{2}$ at an angle of $37^{\circ}$ to the beam, in Cornell geometry. Signals from PIXE and RBS detectors were recorded together with the beam position using the OM_DAQ data acquisition system [9]. Data analysis was carried out using GUPIX [10] for PIXE spectra and SIMNRA [11] for RBS spectra.

Gamma rays were detected with an Ortec HPGe detector mounted outside the chamber on the incident beam direction, $10 \mathrm{~cm}$ behind the analysed sample through a glass window. HPGe detector signals were recorded and treated using Canberra's Genie 2000 software package. Nitrogen stainless steel standard samples $\left(2 \times 1 \times 0.2 \mathrm{~cm}^{3}\right)$ with nitrogen contents between 0.01 and $0.2 \mathrm{wt} . \%$ were used for nitrogen quantification. For analytical purposes, the same method used in a previous work by some of the authors was employed [12]. For nitrogen determination in Amorgos sample, the $7298 \mathrm{keV} y$-ray peak of the ${ }^{14} \mathrm{~N}(\mathrm{~d}, \mathrm{py}){ }^{15} \mathrm{~N}$ nuclear reaction was used. Stopping power corrections were calculated using SRIM-2003 [13] data.

\section{Results and discussion}


PIXE elemental maps were obtained from the Amorgos sample (Fig. 1), and the mica phase was located by the presence of $\mathrm{K}$, since nitrogen was never detected outside those regions where $\mathrm{K}$ was also present. Two different regions of the rock where mica was present (zones 10 and 12) were studied by means of selected area analyses.

Nitrogen content from DIGE results was found to be $0.25 \pm 0.04 \mathrm{wt} . \%$ and $0.32 \pm 0.05 \mathrm{wt} . \%$ in zones 10 and 12, respectively. In order to be able to obtain the overall chemical formulae, quantitative results have to be converted to afu. The results of PIXE spectra fitting using Gupix software for $\mathrm{Al}, \mathrm{Si}, \mathrm{S}, \mathrm{K}, \mathrm{Ca}, \mathrm{Ti}, \mathrm{V}, \mathrm{Cr}, \mathrm{Mn}, \mathrm{Fe}$ and $\mathrm{Zn}$ were combined with $\mathrm{N}$ concentrations obtained by DIGE, and compared to the mean concentrations of the same elements (except for $\mathrm{N}$ ) of paragonite and low-K phengite previously obtained by energy dispersive spectroscopy (EDS) analysis of the same sample. Table 1 shows the combined results of EDS and DIXE/DIGE. These results and specially $\mathrm{K}$ concentration suggest that the analysed regions may contain a mixture of paragonite and phengite, which is perfectly plausible, since the size of the phases found using scanning electron images (BSE) are of the same order of the size of the specific areas analysed by PIXE. However, the high concentration of Fe could also be related to an intergrowth of chlorite. And finally, results confirm that $\mathrm{NH}_{4}$ is replacing $\mathrm{K}$ in the formula of the mica.

The actual phengite proportion in the analysed areas may be calculated as 0.35 for zone 10 and 0.56 for zone 12, taking into account the obtained values for K by PIXE ( 0.18 afu for zone 10 and 0.29 for zone 12) and its real content in pure phengite previously obtained by EMPA and EDS ( $0.52 \mathrm{afu})$. From these data the corresponding $\mathrm{N}$ content in pure mica would be 0.20 afu for zone 10 and 0.16 afu for zone 12 . Such data are in good agreement with those previously predicted for the Amorgos sample, based on indirect approximate methods and criteria [1].

\section{Conclusions}

In this work, nitrogen contents in micas of metamorphic rock has been measured directly for the first time using the ${ }^{14} \mathrm{~N}(\mathrm{~d} \text {, py })^{15} \mathrm{~N}$ nuclear reaction. The combination of IBA techniques such as DIXE and DIGE makes possible the simultaneous analysis of most of the elements in the different mineral phases of a metamorphic rock with high sensitivity and lateral resolution.

The presence of $\mathrm{NH}_{4}$ in the mica has been related to the presence of low-K contents, although the microbeam analysis included a region with a mixture of paragonite and phengite. High Fe contents may also indicate an intergrowth of chlorite. $\mathrm{NH}_{4}$ in micas of organic-matter poor samples may reach values as high as 0.2 afu.

\section{References}

[1] F. Nieto, M.P. Mata, B. Goffé and J.M. Azañón, Geophys. Res. Abs. 5 (2003), p. 09206.

[2] P. Agard, O. Vidal and B. Goffé, J. Metamorph. Geol. 19 (2001), p. 477.

[3] F. Nieto, Am. Mineral. 87 (2002), p. 205.

[4] Á.Z. Kiss, I. Biron, T. Calligaro and J. Salomon, Nucl. Instr. and Meth. B 85 (1994), p. 118.

[5] H. van Bebber, L. Borucki, K. Farzin, Á.Z. Kiss and W.H. Schulte, Nucl. Instr. and Meth. B 136-138 (1998), p. 72.

[6] Z. Elekes, Á.Z. Kiss, I. Biron, T. Calligaro and J. Salomon, Nucl. Instr. and Meth. B 168 (2000), p. 305.

[7] T. Theye, C. Chopin, K.D. Grevel and E.J. Ockenga, Metamorph. Geol. 15 (1997), p. 17. 
[8] J. Garcı'a López, F.J. Ager, M. Barbadillo Rank, M.Á. Ontalba, M.Á. Respaldiza and M.D. Ynsa, Nucl. Instr. and Meth. B 161-163 (2000), p. 1137.

[9] G.W. Grime and M. Dawson, Nucl. Instr. and Meth. B 104 (1995), p. 107.

[10] J.A. Maxwell, J.L. Campbell and W.J. Teesdale, Nucl. Instr. and Meth. B 43 (1989), p. 218.

[11] M. Mayer, SIMNRA User's Guide, Technical Report IPP 9/113, Max-Planck-Institut für Plasmaphysik, Garching, Germany, 1997.

[12] F.J. Ager, S. Elmrabet, A. Paúl, Á. Cea-Naharro, M.D. Ynsa, M.A. Respaldiza and J.A. Odriozola, Nucl. Instr. and Meth. B 188 (2002), p. 96.

[13] J.F. Ziegler, J.P. Biersack and U. Littmark, The Stopping and Range of lons in Solids, Pergamon Press, New York (1985) Available from:http://www.srim.org. 


\section{FIGURE}
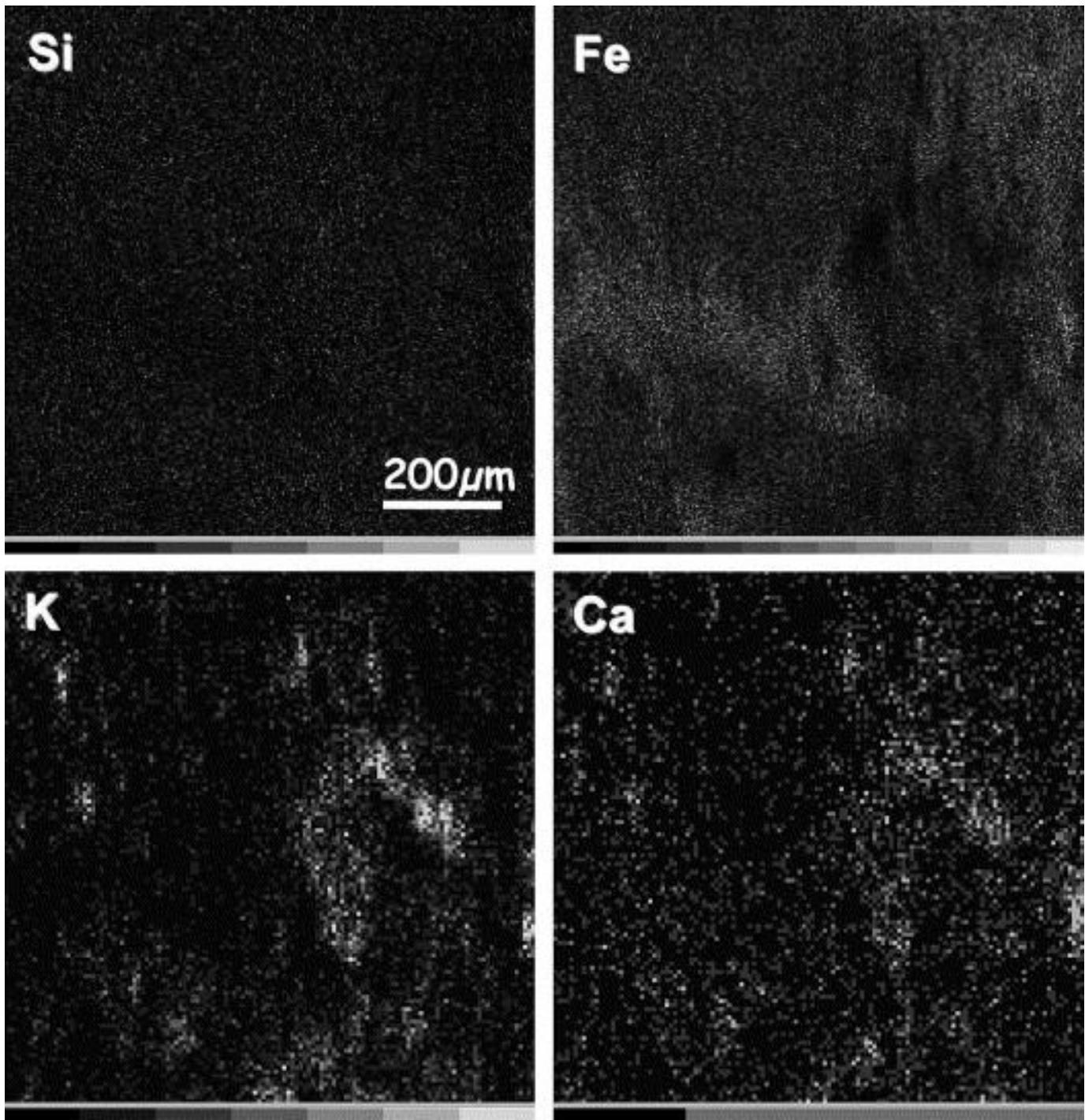

Fig. 1. Elemental distribution maps of $\mathrm{Si}, \mathrm{Fe}, \mathrm{K}$ and $\mathrm{Ca}\left(1000 \times 1000 \mu \mathrm{m}^{2}\right)$ of the zone 10 of the Amorgos sample. Selected area analysis was performed in the $\mathrm{K}$ grain (center-right of the image).

\section{TABLE}

Table 1. Concentrations found in the Amorgos sample for the paragonite and phengite phases (mean concentrations obtained by EDS) and for the mica zones 10 and 12 (obtained by DIXE/DIGE)

\begin{tabular}{|l|l|l|l|l|}
\hline & $\begin{array}{l}\text { Paragonite } \\
\text { (afu } \pm \text { std) }\end{array}$ & $\begin{array}{l}\text { Low-K phengite } \\
\text { (afu } \pm \text { std) }\end{array}$ & Zone 10 (afu \pm std) & Zone 12 (afu \pm std) \\
\hline $\mathrm{Si}$ & $3.070 \pm 0.014$ & $3.22 \pm 0.03$ & $2.915 \pm 0.006$ & $3.060 \pm 0.007$ \\
\hline $\mathrm{Al}$ & $0.930 \pm 0.014$ & $0.78 \pm 0.03$ & $1.085 \pm 0.009$ & $0.940 \pm 0.009$ \\
\hline $\mathrm{Al}(\mathrm{VI})$ & $2.015 \pm 0.021$ & $1.892 \pm 0.022$ & $1.781 \pm 0.015$ & $1.922 \pm 0.019$ \\
\hline $\mathrm{Fe}$ & $0.045 \pm 0.007$ & $0.182 \pm 0.025$ & $(7.513 \pm 0.014) \times 10^{-1}$ & $(4.168 \pm 0.013) \times 10^{-1}$ \\
\hline
\end{tabular}




\begin{tabular}{|l|l|l|l|l|}
\hline & $\begin{array}{l}\text { Paragonite } \\
(\text { afu } \pm \text { std) }\end{array}$ & $\begin{array}{l}\text { Low-K phengite } \\
(\text { afu } \pm \text { std) }\end{array}$ & Zone 10 (afu \pm std) & Zone 12 (afu \pm std) \\
\hline $\mathrm{K}$ & $0.085 \pm 0.007$ & $0.52 \pm 0.05$ & $(1.811 \pm 0.003) \times 10^{-1}$ & $(2.888 \pm 0.005) \times 10^{-1}$ \\
\hline $\mathrm{NH}_{4}$ & & & $0.070 \pm 0.011$ & $0.090 \pm 0.014$ \\
\hline $\mathrm{Ti}$ & & 0.01 & $(0.553 \pm 0.006) \times 10^{-2}$ & $(0.781 \pm 0.008) \times 10^{-2}$ \\
\hline $\mathrm{Mn}$ & 0.01 & & $(0.520 \pm 0.014) \times 10^{-2}$ & $(0.294 \pm 0.013) \times 10^{-2}$ \\
\hline $\mathrm{Ca}$ & 0.01 & 0.01 & $(0.096 \pm 0.004) \times 10^{-1}$ & $(0.056 \pm 0.006) \times 10^{-1}$ \\
\hline $\mathrm{Na}$ & $0.69 \pm 0.05$ & $0.085 \pm 0.006$ & $\mathrm{nd}$ & $\mathrm{nd}$ \\
\hline $\mathrm{Cr}$ & & & $(0.211 \pm 0.009) \times 10^{-2}$ & $(0.136 \pm 0.010) \times 10^{-2}$ \\
\hline $\mathrm{V} \mathrm{O}_{3}$ & & & $(0.310 \pm 0.011) \times 10^{-2}$ & $(0.343 \pm 0.015) \times 10^{-2}$ \\
\hline $\mathrm{ZnO}$ & & & $(0.047 \pm 0.003) \times 10^{-1}$ & $(0.025 \pm 0.003) \times 10^{-1}$ \\
\hline
\end{tabular}

Sodium was not detected by PIXE. 